\title{
Comparison Between Three- and Four-coil Wireless Power Transfer Systems with Resonant Coils
}

\author{
Fábio B. de Moraes ${ }^{1}$ (D), Paulo J. Abatti ${ }^{1}$ (D), \\ ${ }^{1}$ Fábio B. de Moraes and Paulo J. Abatti - Graduate School of Electrical Engineering and Computer Science \\ (CPGEI), Federal University of Technology-Paraná (UTFPR) - Av. Sete de Setembro, 3165 - Rebouças CEP \\ 80230-901 - Curitiba - PR - Brasil - fbrignol@utfpr.edu.br, abatti@utfpr.edu.br
}

\begin{abstract}
In this paper, it is demonstrated that the efficiency and ability to transfer power to the load in three-coil wireless power transfer (WPT) systems are always higher than in equivalent fourcoil ones. On the other hand, it is shown that there are features attainable in four-coil WPT system that are not in three-coil ones. For instance, in a four-coil WPT system, which can be divided into source, two communication, and load circuits, it is possible to devise a method for which the maximum power transferred to the load circuit or the maximum efficiency do not depend on the mutual inductance between the two communication coils, independently of the load resistance value. The necessary conditions to achieve the above feature together with the overall circuit analysis are discussed in details and practical results presented.
\end{abstract}

Index Terms - four-coil, power transfer efficiency, three-coil, wireless power transfer systems.

\section{INTRODUCTION}

Among the several forms of energy, whenever possible, the electrical one is preferable as produces less pollution comparatively, it is easier to handle, and mainly because it can be transmitted more efficiently. The usual method to transmit electrical energy from the source to the load is via cables or wires. However, from the very beginning of electrical energy distribution history, it was recognized that wireless methods to transmit it would be comparatively more convenient [1].

Nevertheless, after the pioneering work of Tesla, which used an inductive link, composed of two coils tuned at the same resonance frequency to transmit electrical energy at a given distance [2], the investigation of the so-called wireless power transfer (WPT) systems was almost neglected for several years, but by some sparse works [3]-[9]. In fact, only about a decade ago the three- [10]-[18], and four-coil [19]-[30] WPT systems had been introduced. WPT systems using more than four coils had also been investigated, but most of the research effort in the area had been focused in the three- and four-coil configurations [25], [31], [32]. Here it is important to emphasize that the three- and four-coil WPT systems are, in some aspects, similar to the two-coil WPT systems, e.g., they have one coil connected to the source and one connected to the load. The differences are that the three-coil WPT systems have one additional (communication) coil and the four-coil WPT systems have two additional (communication) coils. Moreover, following Tesla's original approach [2], all coils are tuned at the same resonance frequency and mutual inductance of non-adjacent coils are made as small as possible.

Anyway, perhaps because it is a relatively recent circuit configuration, the three- and four-coil WPT systems characteristics are still object of studies. For example, in a recent paper it was demonstrated 
that in a three-coil WPT system both the maximum efficiency $\left(\eta_{3_{\max }}\right)$ and maximum power transferred to the load $\left(P_{3_{\max }}\right)$ depend on neither the mutual inductance between the coils of the communication and load circuits nor the load resistance value $\left(R_{L}\right)$ [17]. This means that $\eta_{3_{\max }}$ and $P_{3_{\max }}$ are only determined by the source and communication circuits parameters, a feature that may be relevant to those involved in the circuit implementation. However, this also means that given a load resistance value there is only one value of the mutual inductance between the coils of the communication and load circuits, and vice-versa, for which either the maximum power transferred to the load circuit or the efficiency are maximum, restricting its practical application.

The aim of this work is to show that in four-coil WPT systems the maximum efficiency or maximum power transferred to the load do not depend on mutual inductance between the coils of the communication circuits (M23) independently of the load resistance value, and vice-versa. This is done by adjusting the mutual inductance between the coil at the last communication circuit and that at the load circuit (M34). In order to demonstrate this feature it is important to compare the three- and four-coil WPT systems, for it is demonstrated that the efficiency and the ability to transfer power to the load in threecoil WPT systems are always higher than in equivalent four-coil ones. Thus, the mutual inductance (proportional to distance in a coaxial arrangement) between the coils of the communication circuits were preserved in both three- and four-coil WPT systems. The necessary conditions to attain the above feature as well as the overall circuit analysis are discussed in details and experimental results, used to validate the theoretical analysis, presented.

\section{Circuit AnAlysis}

Figure 1 shows the schematic view of a four-coil WPT system. Following Tesla's original approach [2], all circuits should be tuned at the same resonance angular frequency $\left(\omega_{0}^{-1}=\sqrt{L_{1} C_{1}}=\sqrt{L_{2} C_{2}}=\right.$ $\left.\sqrt{L_{3} C_{3}}=\sqrt{L_{4} C_{4}}\right)$, and the mutual inductances between non-adjacent coils should be as small as possible $\left(M_{13}=M_{14}=M_{24}=0\right)$. Under the above conditions, the currents and voltages at each coil circuit are in phase so that possible losses due to reactive effects are reduced.

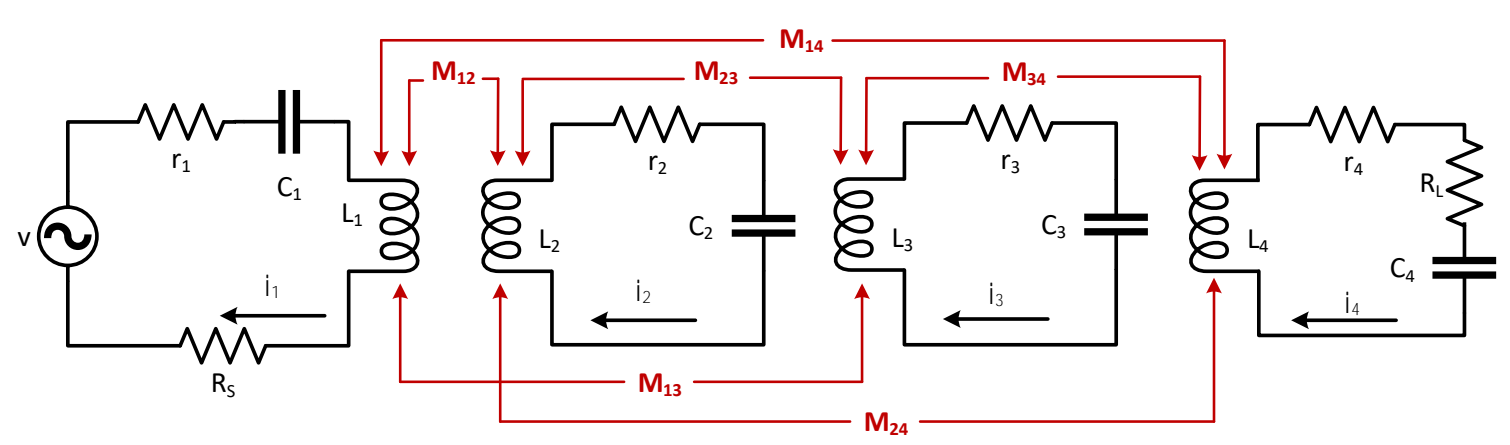

Fig. 1. Schematic representation of a four-coil wireless power transfer system.

These considerations allow to write the power dissipated at the load circuit $\left(P_{4}\right)$ as

$$
P_{4}=R_{4} \cdot\left|i_{4}\right|^{2}=\frac{R_{4} v^{2} \omega_{0}^{2} M_{12}^{2} \omega_{0}^{2} M_{23}^{2} \omega_{0}^{2} M_{34}^{2}}{\left(\left(R_{1} r_{2}+\omega_{0}^{2} M_{12}^{2}\right)\left(r_{3} R_{4}+\omega_{0}^{2} M_{34}^{2}\right)+R_{1} R_{4} \omega_{0}^{2} M_{23}^{2}\right)^{2}},
$$


where $M_{12}, M_{23}$, and $M_{34}$ are the remaining mutual inductances, $v$ the source open-terminal voltage (when $i_{1}=0$ ), $R_{1}$ the sum of the source resistance and the total internal resistance of $L_{1}$ and $C_{1}$ $\left(R_{1}=R_{s}+r_{1}\right), r_{2}$ and $r_{3}$ the total internal resistances of $L_{2}$ and $C_{2}$, and $L_{3}$ and $C_{3}$, respectively, and $R_{4}$ the sum of the load resistance and the total internal resistance of $L_{4}$ and $C_{4}\left(R_{4}=R_{L}+r_{4}\right)$.

The total power supplied by the voltage source can be easily calculated $\left(P_{T}=v \cdot i_{1}\right)$ giving

$$
P_{T}=\frac{r_{2} r_{3} R_{4}+r_{2} \omega_{0}^{2} M_{34}^{2}+R_{4} \omega_{0}^{2} M_{23}^{2}}{\left(R_{1} r_{2}+\omega_{0}^{2} M_{12}^{2}\right)\left(r_{3} R_{4}+\omega_{0}^{2} M_{34}^{2}\right)+R_{1} R_{4} \omega_{0}^{2} M_{23}^{2}} .
$$

Thus, the system efficiency $\left(\eta=P_{4} / P_{T}\right)$ can be written as

$$
\eta=\frac{R_{4} \omega_{0}^{2} M_{12}^{2} \omega_{0}^{2} M_{23}^{2} \omega_{0}^{2} M_{34}^{2}}{\left(\left(R_{1} r_{2}+\omega_{0}^{2} M_{12}^{2}\right)\left(r_{3} R_{4}+\omega_{0}^{2} M_{34}^{2}\right)+R_{1} R_{4} \omega_{0}^{2} M_{23}^{2}\right)\left(r_{2} r_{3} R_{4}+r_{2} \omega_{0}^{2} M_{34}^{2}+R_{4} \omega_{0}^{2} M_{23}^{2}\right)}
$$

It is important to emphasize that if one calculates the efficiency considering only the power delivered to the load $\left(\eta_{L}\right)$, since the same current $i_{4}$ flows through $r_{4}$ and $R_{L}$, the power $P_{4}$ can be splitted using the ratio of a voltage divider. Thus, $P_{R L}=P_{4} \cdot R_{L} /\left(R_{L}+r_{4}\right)$ and the efficiency is $\eta_{L}=\eta \cdot R_{L} /\left(R_{L}+r_{4}\right)$. In a similar manner, if only the efficiency of the link transmission $\left(\eta_{L I N K}\right)$ is to be analyzed (excluding the generator resistance, $\left.R_{S}\right)$, it can be written $\eta=\eta_{L I N K} \cdot R_{1}^{*} /\left(R_{S}+R_{1}^{*}\right)$, where $R_{1}^{*}$ is the sum of $r_{1}$ and the reflected resistance [33] from communication and load circuits into the source circuit. Moreover, at first glance, the WPT systems should be designed to transmit the maximum amount of power from the source to the load (located as far as possible) with maximum efficiency. However, the maximum power transfer theorem teaches that the maximum transference of power is attained with an overall system efficiency of only 50\%, higher efficiencies meaning a relatively reduced amount of power transferred to the load [25], [26], [34]. Thus, it is necessary to know a priori whether the WPT system is designed to optimize efficiency or if the amount of power transferred to load is to be the maximum [26].

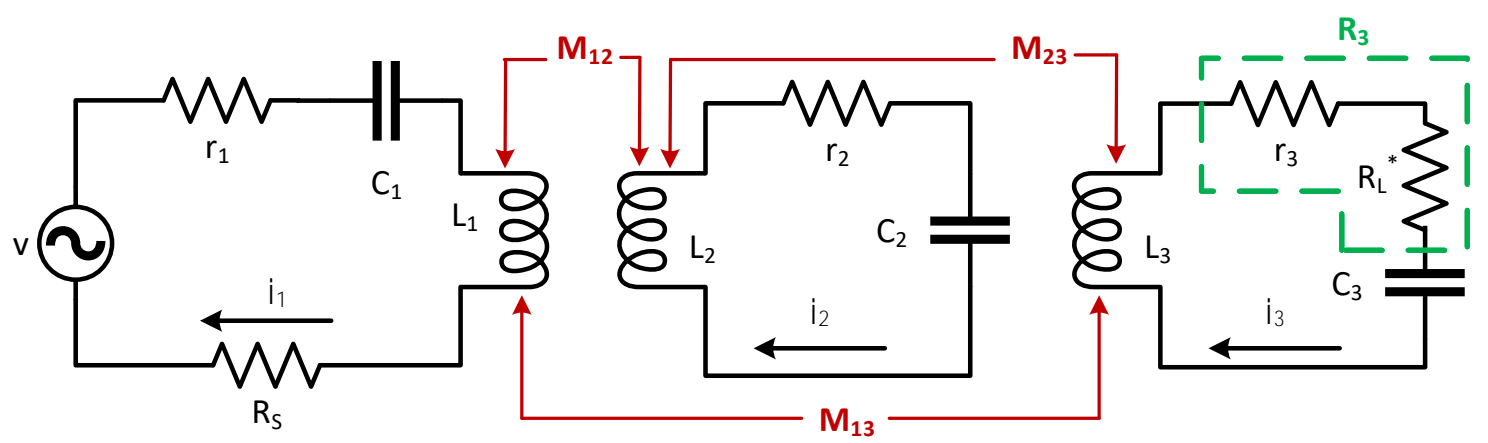

Fig. 2. Schematic representation of a three-coil wireless power transfer system.

Anyway, in order to help a comparative analysis, figure 2 shows the schematic view of the three-coil WPT system. Observe that the four-coil WPT system can be transformed into a three-coil equivalent one, reflecting $R_{4}$ [33] into the second communication circuit (see figure 2). In other words, both three-coil and four-coil WPT systems are equivalent whenever (see figure 2)

$$
R_{L}^{*}=\frac{\omega_{0}^{2} M_{34}^{2}}{R_{4}}
$$

Brazilian Microwave and Optoelectronics Society-SBMO Brazilian Society of Electromagnetism-SBMag received 17 June 2020; for review 20 June 2020; accepted 19 Jan 2021 (C) 2021 SBMO/SBMag (cc) BY

ISSN 2179-1074 
In addition, it is possible to define

$$
R_{3}=r_{3}+R_{L}^{*}
$$

so that the power transferred to $R_{3}$ in a three-coil WPT system $\left(P_{3}\right)$ and efficiency $\left(\eta_{3}\right)$ can be given by

$$
P_{3}=R_{3} .\left|i_{3}\right|^{2}=\frac{R_{3} v^{2} \omega_{0}^{2} M_{12}^{2} \omega_{0}^{2} M_{23}^{2}}{\left(\left(R_{1} r_{2}+\omega_{0}^{2} M_{12}^{2}\right) R_{3}+R_{1} \omega_{0}^{2} M_{23}^{2}\right)^{2}},
$$

and

$$
\eta_{3}=\frac{R_{3} \omega_{0}^{2} M_{12}^{2} \omega_{0}^{2} M_{23}^{2}}{\left(\left(R_{1} r_{2}+\omega_{0}^{2} M_{12}^{2}\right) R_{3}+R_{1} \omega_{0}^{2} M_{23}^{2}\right)\left(r_{2} R_{3}+\omega_{0}^{2} M_{23}^{2}\right)},
$$

respectively.

Dividing (1) by (6) and (3) by (7), and using (4) and (5) yield

$$
\frac{P_{4}}{P_{3}}=\frac{\eta_{4}}{\eta_{3}}=\frac{\frac{\omega_{0}^{2} M_{34}^{2}}{R_{4}}}{r_{3}+\frac{\omega_{0}^{2} M_{34}^{2}}{R_{4}}} .
$$

Therefore, the three-coil WPT systems always present better performance than the four-coil ones $\left(P_{3}>P_{4}\right.$ and $\left.\eta_{3}>\eta_{4}\right)$.

However, there are situations that performance should be relegated to a second plan to attend some practical demand. For instance, it can be easily demonstrated that in the three-coil WPT system the $M_{23}$ for maximum power transferred to $R_{3}\left(M_{23-P_{3 M A X}}\right)$ and $M_{23}$ for maximum efficiency $\left(M_{23-\eta_{3 M A X}}\right)$ can be written [17] as

$$
M_{23-P_{3 M A X}}=\frac{1}{\omega_{0}} \sqrt{\frac{R_{1} r_{2}+\omega_{0}^{2} M_{12}^{2}}{R_{1}} R_{3}}
$$

and

$$
M_{23-\eta_{3 M A X}}=\frac{1}{\omega_{0}} \sqrt{\sqrt{\frac{r_{2}}{R_{1}}} \sqrt{R_{1} r_{2}+\omega_{0}^{2} M_{12}^{2}} R_{3}},
$$

respectively.

Substituting (9) and (10) into (6) and (7) yield

$$
P_{3 M A X}=\frac{v^{2}}{4 R_{1}} \frac{\omega_{0}^{2} M_{12}^{2}}{R_{1} r_{2}+\omega_{0}^{2} M_{12}^{2}},
$$

and

$$
\eta_{3 M A X}=\frac{\omega_{0}^{2} M_{12}^{2}}{\left(\sqrt{R_{1} r_{2}}+\sqrt{R_{1} r_{2}+\omega_{0}^{2} M_{12}^{2}}\right)^{2}},
$$

respectively.

Note that, as already pointed out in [17], (11) and (12) are independent on either $M_{23}$ and $R_{3}$, i.e., $P_{3 M A X}$ or $\eta_{3 M A X}$ are determined exclusively by the source and communication circuits' parameters. However, (9) and (10) show also that for a given $R_{3}$, and consequently for a given load $R_{L}^{*}=R_{L}$, there is only one value of $M_{23}$ for which $P_{3}$ or $\eta_{3}$ can be maximum, and this specific value of $M_{23}$ may not be attainable.

On the other hand, in four-coil WPT systems, using (4) and (5) into (9), and substituting (11) into (8), and using $R_{4}=r_{4}+R_{L}$, yield 


$$
M_{23-P_{4 M A X}}=\frac{1}{\omega_{0}} \sqrt{\left(\frac{R_{1} r_{2}+\omega_{0}^{2} M_{12}^{2}}{R_{1}}\right)\left(r_{3}+\frac{\omega_{0}^{2} M_{34}^{2}}{r_{4}+R_{L}}\right)},
$$

and

$$
P_{4 M A X}=\frac{v^{2}}{4 R_{1}} \frac{\omega_{0}^{2} M_{12}^{2}}{R_{1} r_{2}+\omega_{0}^{2} M_{12}^{2}} \frac{\frac{\omega_{0}^{2} M_{34}^{2}}{r_{4}+R_{L}}}{r_{3}+\frac{\omega_{0}^{2} M_{34}^{2}}{r_{4}+R_{L}}},
$$

respectively, whereas using (4) and (5) into (10), and substituting (12) into (8), and also using $R_{4}=$ $r_{4}+R_{L}$, give

$$
M_{23-\eta_{4 M A X}}=\frac{1}{\omega_{0}} \sqrt{\sqrt{\frac{r_{2}}{R_{1}}} \sqrt{R_{1} r_{2}+\omega_{0}^{2} M_{12}^{2}}\left(r_{3}+\frac{\omega_{0}^{2} M_{34}^{2}}{r_{4}+R_{L}}\right)},
$$

and

$$
\eta_{4 M A X}=\frac{\omega_{0}^{2} M_{12}^{2}}{\left(\sqrt{R_{1} r_{2}}+\sqrt{R_{1} r_{2}+\omega_{0}^{2} M_{12}^{2}}\right)^{2}} \frac{\frac{\omega_{0}^{2} M_{34}^{2}}{r_{4}+R_{L}}}{r_{3}+\frac{\omega_{0}^{2} M_{34}^{2}}{r_{4}+R_{L}}},
$$

respectively.

Observe that independently of $R_{L}$ used, the value of $M_{34}$ might be adjusted so that an adequate value of $M_{23}$ may be obtained, allowing $P_{4}$ or $\eta_{4}$ to be maximum. In other words, in a four-coil WPT system the $M_{34}$ can be used as an "impedance match" circuit desvinculating the actual $R_{L}$ value from the determination of $M_{23}$ which allows $P_{4}$ or $\eta_{4}$ to be maximum.

\section{EXPERIMENTAL RESULTS}

For the experimental evaluation of the mathematical analysis, four coils with equal dimensions and shapes were built. The coils are circular with diameter of $150 \mathrm{~mm}$ and $22 \mathrm{~mm}$ of length, wound with 23 turns of enameled copper 20 AWG wire in a single layer way. The coils have self-inductance of $138.67 \pm 0.21 \mu \mathrm{H}$ with internal resistances of $3.41 \pm 0.09 \Omega$. All measurements were made using an Agilent precision vector impedance analyzer (model 4294A) operating at $552 \mathrm{kHz}$. In order to obtain the practical value of the mutual inductance the coils were arranged coaxially, the value of the coupling coefficient $(k)$ was measured, and then using $M_{p s}=k \sqrt{L_{p} L_{s}}$ the mutual inductance was determined as follows: the primary coil was excited by a signal generator (Rigol model DG1022) with a voltage vp, whereas the open-terminal voltage of the secondary coil, vs, was taken. Both voltages were measured with the aid of a digital oscilloscope (Tektronix model TDS2012C). The frequency of the exciting voltage was adjusted to a relatively low value $(\approx 10 \mathrm{kHz})$ to reduce the possible influence of the coils' stray capacitances. It can be easily demonstrated that $k=v_{p} / v_{s}$, whenever $L_{p} \approx L_{s}$ [26]. Figure 3 shows the measured mutual inductance as a function of the distance between the coils coaxially aligned.

Commercial capacitors of $560 p F$ were used to tune the circuits (the practical values was $556 \pm 7 p F$ ), with a variable capacitor (trimmer) in parallel, achieving the series resonance value of $552 \mathrm{kHz}$. This frequency has been selected due to its handiness in tuning the circuits, and because it does not present adverse health effects [35], [36]. The resistances of the capacitors at $552 \mathrm{kHz}$ were neglected because they were in order of milliohms. 


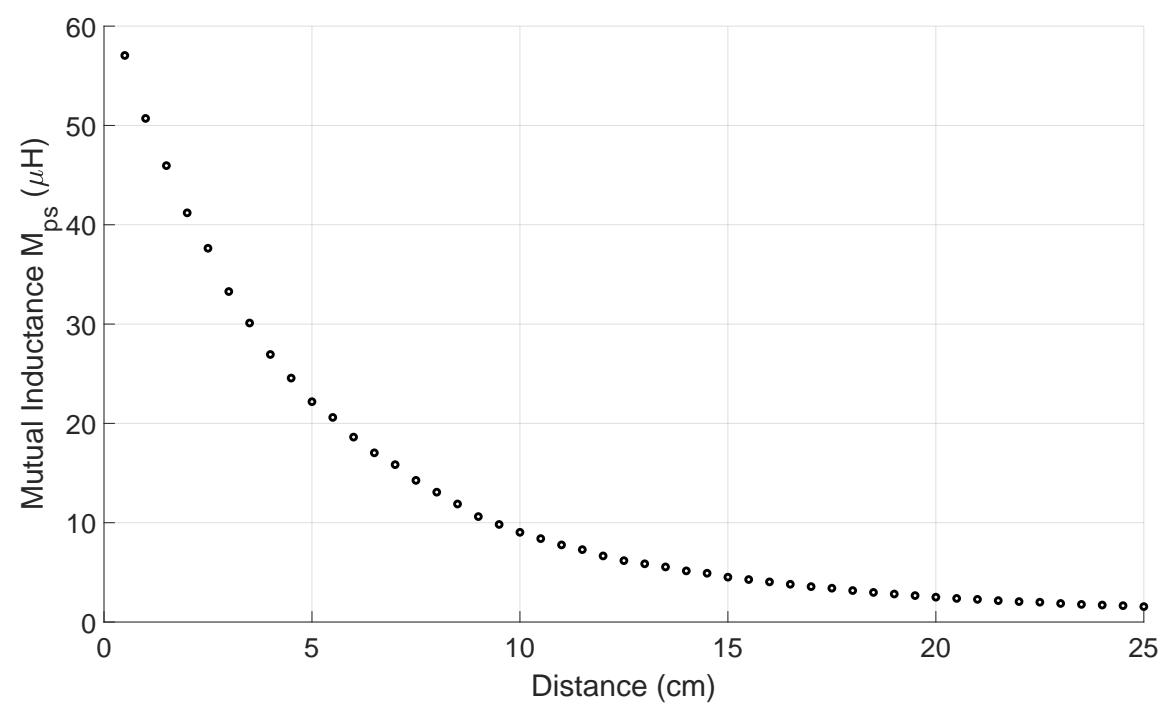

Fig. 3. Experimental mutual inductance in function of distance for coils coaxially aligned.

The measured (at $552 \mathrm{kHz}$ ) values of the load $\left(R_{L}\right)$ used in the experiments were $5.67 \Omega, 8.24 \Omega, 9.97 \Omega$, $12.03 \Omega, 17.98 \Omega, 21.77 \Omega$ and $46.95 \Omega$. The parasitic self-inductance of the resistors were neglected because they were in order of nanohenry.

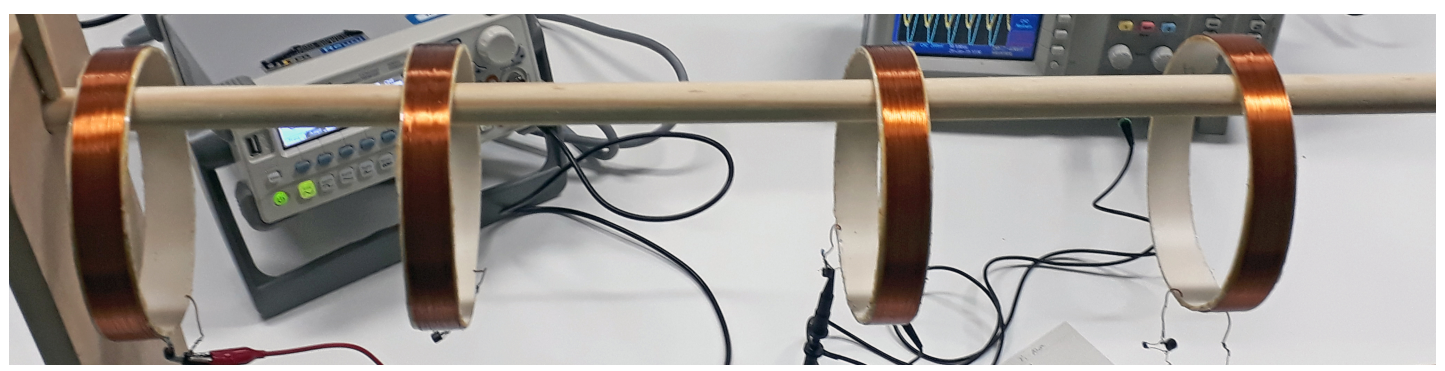

Fig. 4. Experimental setup of the four-coil wireless power transfer system.

Figure 4 shows the implemented four-coil WPT system. The coil of the source circuit was fixed to the left end of a wood support, whereas the second coil was fixed $12.5 \mathrm{~cm}$ apart. The value of $M_{12}$ was $6.18 \mu \mathrm{H}$ (see figure 3). A sinusoidal voltage signal $(v)$ of $7.1 V_{R M S}$ with a frequency of $552 \mathrm{kHz}$, internal resistance $\left(R_{s}\right)$ of $50.53 \Omega$ (Rigol signal generator - DG1022) was used as the voltage source. The current at the source circuit $\left(i_{1}\right)$ was determined to measure the voltage at a series resistor $(\mathrm{r}=$ $1.02 \Omega)$. Therefore, the value of $R_{1}\left(=r_{1}+r+R_{s}\right)$ used in the calculations was $54.89 \Omega$. During the experiments the phase between $v$ and $i_{1}$ was continuously monitored (ideally it must be zero) to certify that the influence of $M_{13}, M_{14}$, and $M_{24}$ could in fact be neglected.

The value of $i_{3}$ in the three-coil and $i_{4}$ in the four-coil WPT systems, respectively, were determined by measuring the voltages at the used loads, and the powers at the load circuits $\left(P_{3}=R_{3} \cdot\left|i_{3}\right|^{2}\right.$ and $\left.P_{4}=R_{4} \cdot\left|i_{4}\right|^{2}\right)$ were calculated. 
From equations (14) and (16) it can be defined as a multiplying factor $(F)$

$$
F=\frac{\frac{\omega_{0}^{2} M_{34}^{2}}{r_{4}+R_{L}}}{r_{3}+\frac{\omega_{0}^{2} M_{34}^{2}}{r_{4}+R_{L}}} .
$$

The maximum power transferred to the load circuit $\left(P_{4 M A X}\right)$, and the maximum efficiency $\left(\eta_{4 M A X}\right)$, both as a function of $R_{L}$ for $F$ equal to $1 / 2,2 / 3$ and 5/6, are shown in figures $5(\mathrm{a})$ and $5(\mathrm{~b})$, respectively. Firstly, the experiments were performed keeping $M_{23}$ fixed at $3.4 \mu H$. Then, just to check the independence between $R_{L}$ and $M_{23}$ the experiments were repeated keeping $M_{23}$ fixed at $5.55 \mu \mathrm{H}$. In addition, for comparison purposes, the values of $P_{3 M A X}$ and $\eta_{3 M A X}$ for $M_{23}=3.4 \mu \mathrm{H}$ and $M_{23}=$ $5.55 \mu \mathrm{H}$ were also plotted in figures $5(\mathrm{a})$ and $5(\mathrm{~b})$, respectively.

Evidently, in the four-coil WPT system each time $R_{L}$ was changed the relative position of $L_{4}$ was modified so that $\left(\omega_{0}^{2} M_{34}^{2}\right) /\left(R_{L}+r_{4}\right)$ was kept constant. 


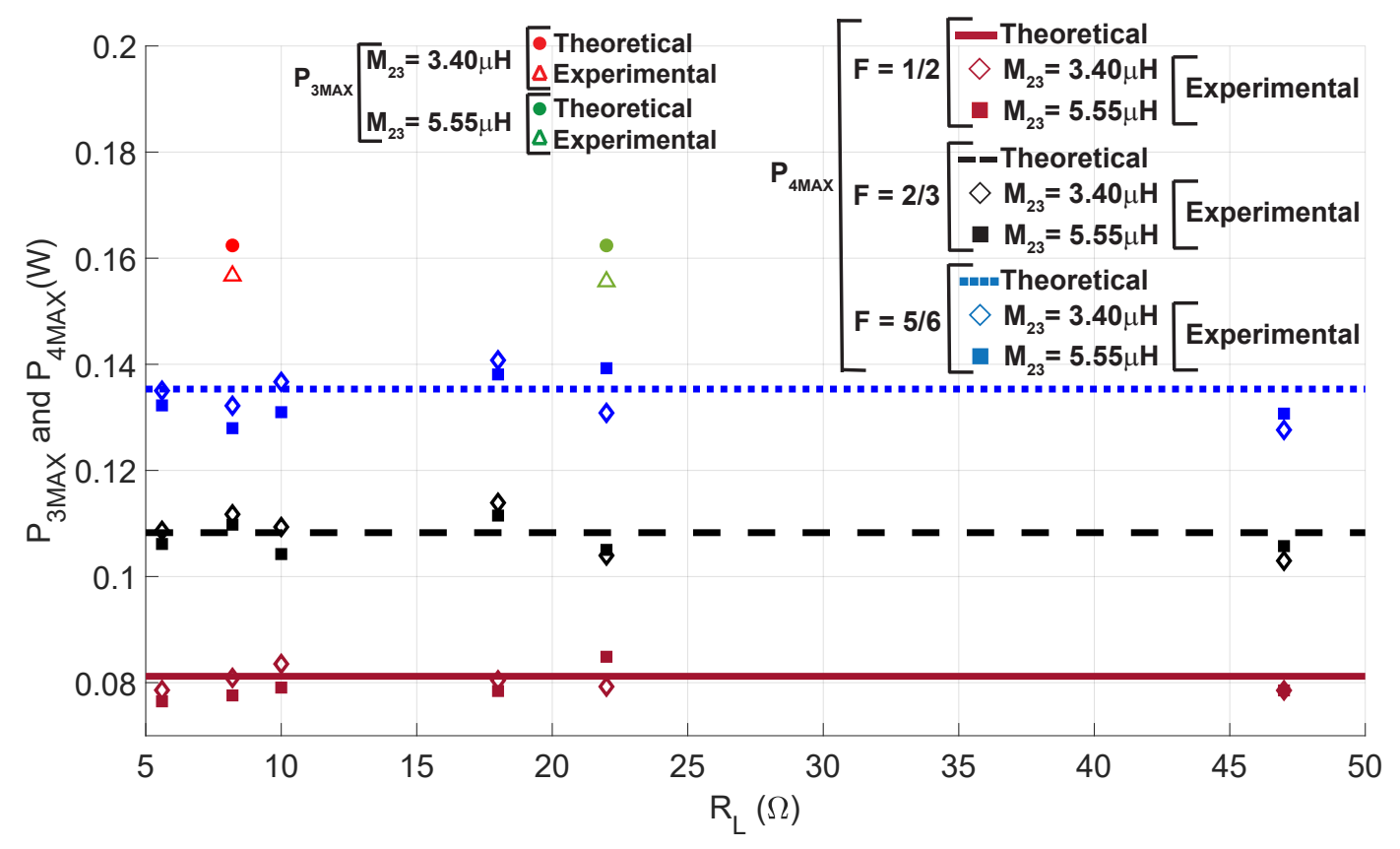

(a)

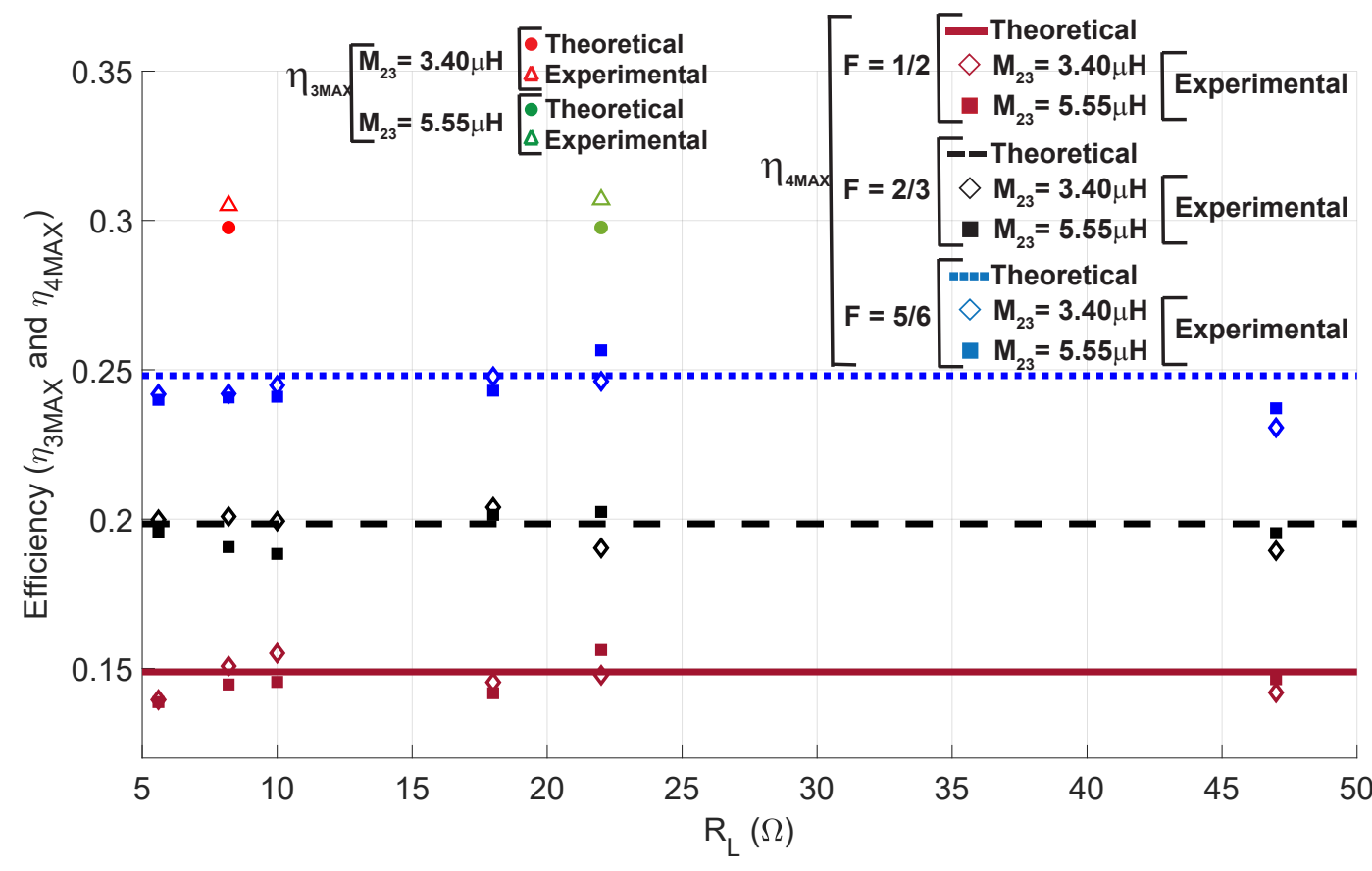

(b)

Fig. 5. Experimental results of (a) maximum power transferred to the load circuit and (b) maximum efficiency, both as a function of $R_{L}$ in a four-coil WPT system. For comparison purposes the values of $P_{3 M A X}$ and $\eta_{3 M A X}$ for $M_{23}=3.4 \mu H$ and $M_{23}=5.55 \mu \mathrm{H}$ were also plotted in figures 5(a) and 5(b), respectively. 


\section{CONCLUSION}

The three- and four-coil WPT systems have been compared, showing that in the four-coil ones neither the maximum power transferred to the load nor the maximum efficiency depends on the mutual inductance regardless of the on load resistance value, provided $\left(\omega^{2} M_{34}^{2}\right) /\left(R_{L}+r_{4}\right)$ is kept constant. Although the maximum power transferred to the load or maximum efficiency of four-coil are always smaller than those of three-coil WPT systems, the demonstrated feature allows designing optimized WPT systems independent on load resistance value whenever the four-coil configuration is used, which is not possible with three-coil WPT systems.

\section{REFERENCES}

[1] A. Marincic, "Nikola Tesla and the Wireless Transmission of Energy," IEEE Transactions on Power Apparatus and Systems, vol. PAS-101, no. 10, pp. 4064-4068, oct 1982. [Online]. Available: http://ieeexplore.iee.org/document/ $4111223 /$

[2] N. Tesla, "Apparatus for Transmitting Electrical Energy,” p. 4, 1914. [Online]. Available: http://large.stanford.edu/ courses/2014/ph240/ho1/docs/US1119732.pdf

[3] W. H. Ko, S. P. Liang, and C. D. F. Fung, "Design of radio-frequency powered coils for implant instruments," Medical Biological Engineering Computing, vol. 15, no. 6, pp. 634-640, nov 1977. [Online]. Available: http://link.springer.com/10.1007/BF02457921

[4] W. Brown, "The History of Power Transmission by Radio Waves," IEEE Transactions on Microwave Theory and Techniques, vol. 32, no. 9, pp. 1230-1242, sep 1984. [Online]. Available: http://ieeexplore.iee.org/document/1132833/

[5] M. Soma, D. C. Galbraith, and R. L. White, "Radio-Frequency Coils in Implantable Devices: Misalignment Analysis and Design Procedure," IEEE Transactions on Biomedical Engineering, vol. BME-34, no. 4, pp. 276-282, apr 1987. [Online]. Available: http://ieeexplore.ieee.org/document/4122531/

[6] K. Van Schuylenbergh, R. Puers, F. Rodes, F. Bumy, M. Donkerwolcke, and F. Moulart, "Monitoring orthopaedic implants using active telemetry," in Proceedings of the Annual International Conference of the IEEE Engineering in Medicine and Biology Society, pp. 2672-2673, oct 1992. [Online]. Available: http://ieeexplore.ieee.org/document/5761503/

[7] G. Vandevoorde and R. Puers, "Wireless energy transfer for stand-alone systems: a comparison between low and high power applicability," Sensors and Actuators A: Physical, vol. 92, no. 1-3, pp. 305-311, aug 2001. [Online]. Available: https://linkinghub.elsevier.com/retrieve/pii/S092442470100588X

[8] S. Pichorim and P. Abatti, "Design of Coils for Millimeter- and Submillimeter-Sized Biotelemetry," IEEE Transactions on Biomedical Engineering, vol. 51, no. 8, pp. 1487-1489, aug 2004. [Online]. Available: http://www.ncbi.nlm.nih.gov/pubmed/15311836http://ieeexplore.ieee.org/document/1315873/

[9] G. Wang, W. Liu, M. Sivaprakasam, and G. Kendir, "Design and analysis of an adaptive transcutaneous power telemetry for biomedical implants," IEEE Transactions on Circuits and Systems I: Regular Papers, vol. 52, no. 10, pp. 2109-2117, oct 2005. [Online]. Available: http://ieeexplore.ieee.org/document/1519624/

[10] M. Kiani, Uei-Ming Jow, and M. Ghovanloo, "Design and Optimization of a 3-Coil Inductive Link for Efficient Wireless Power Transmission,” IEEE Transactions on Biomedical Circuits and Systems, vol. 5, no. 6, pp. 579-591, dec 2011. [Online]. Available: http://ieeexplore.ieee.org/document/5951804/

[11] L. Sun, H. Tang, and Y. Zhang, "Determining the Frequency for Load-Independent Output Current in Three-Coil Wireless Power Transfer System," Energies, vol. 8, no. 9, pp. 9719-9730, sep 2015. [Online]. Available: http://www.mdpi.com/1996-1073/8/9/9719

[12] Y. Yi, U. Buttner, Y. Fan, and I. G. Foulds, "Design and optimization of a 3-coil resonance-based wireless power transfer system for biomedical implants," International Journal of Circuit Theory and Applications, vol. 43, no. 10, pp. 1379-1390, oct 2015. [Online]. Available: http://doi.wiley.com/10.1002/cta.2024

[13] W. X. Zhong, C. Zhang, X. Liu, and S. Y. R. Hui, "A Methodology for Making a Three-Coil Wireless Power Transfer System More Energy Efficient Than a Two-Coil Counterpart for Extended Transfer Distance," IEEE Transactions on Power Electronics, vol. 30, no. 2, pp. 933-942, feb 2015. [Online]. Available: http: //ieeexplore.ieee.org/lpdocs/epic03/wrapper.htm?arnumber=6774973

[14] W. Niu, J. Wang, J. Chu, and W. Gu, "Optimal single relay position of a 3-coil wireless power transfer system," The Journal of Engineering, vol. 2016, no. 7, pp. 249-252, jul 2016. [Online]. Available: https://digital-library.theiet.org/content/journals/10.1049/joe.2016.0082 
[15] U. Surendrakumaran and A. Nachiappan, "Performance analysis of wireless power transfer(WPT) through two-coil and three-coil structure," in 2017 International Conference on Innovative Research In Electrical Sciences (IICIRES), pp. 1-6, jun 2017. [Online]. Available: http://ieeexplore.ieee.org/document/8078308/

[16] J. Zhang, X. Yuan, C. Wang, and Y. He, "Comparative Analysis of Two-Coil and Three-Coil Structures for Wireless Power Transfer," IEEE Transactions on Power Electronics, vol. 32, no. 1, pp. 341-352, jan 2017. [Online]. Available: http://ieeexplore.ieee.org/document/7401100/

[17] P. J. Abatti, C. M. de Miranda, M. A. da Silva, and S. F. Pichorim, "Analysis and optimisation of three-coil wireless power transfer systems," IET Power Electronics, vol. 11, no. 1, pp. 68-72, jan 2018. [Online]. Available: https://digital-library.theiet.org/content/journals/10.1049/iet-pel.2016.0492

[18] R. Lu, M. R. Haider, and Y. Massoud, "A Three-Coil Coupled High-Efficiency Power Link for Wireless Power Transfer Application," in 2019 IEEE 20th Wireless and Microwave Technology Conference (WAMICON), pp. 1-4, apr 2019. [Online]. Available: https://ieeexplore.ieee.org/document/8765470/

[19] A. Kurs, A. Karalis, R. Moffatt, J. D. Joannopoulos, P. Fisher, and M. Soljacic, "Wireless Power Transfer via Strongly Coupled Magnetic Resonances," Science, vol. 317, no. 5834, pp. 83-86, jul 2007. [Online]. Available: http://www.sciencemag.org/cgi/doi/10.1126/science.1143254

[20] Chih-Jung Chen, Tah-Hsiung Chu, Chih-Lung Lin, and Zeui-Chown Jou, "A Study of Loosely Coupled Coils for Wireless Power Transfer," IEEE Transactions on Circuits and Systems II: Express Briefs, vol. 57, no. 7, pp. 536-540, jul 2010. [Online]. Available: http://ieeexplore.ieee.org/document/5475182/

[21] A. P. Sample, D. A. Meyer, and J. R. Smith, "Analysis, experimental results, and range adaptation of magnetically coupled resonators for wireless power transfer," IEEE Transactions on Industrial Electronics, vol. 58, no. 2, pp. 544-554, 2011.

[22] S. Cheon, Y.-H. Kim, S.-Y. Kang, M. L. Lee, J.-M. Lee, and T. Zyung, "Circuit-Model-Based Analysis of a Wireless Energy-Transfer System via Coupled Magnetic Resonances,” IEEE Transactions on Industrial Electronics, vol. 58, no. 7, pp. 2906-2914, jul 2011. [Online]. Available: http://ieeexplore.ieee.org/document/5560805/

[23] Y. Zhang, Z. Zhao, and K. Chen, "Frequency-Splitting Analysis of Four-Coil Resonant Wireless Power Transfer," IEEE Transactions on Industry Applications, vol. 50, no. 4, pp. 2436-2445, jul 2014. [Online]. Available: http://ieeexplore.ieee.org/document/6682994/

[24] S. Huang, Z. Li, Y. Li, X. Yuan, and S. Cheng, "A Comparative Study Between Novel and Conventional Four-Resonator Coil Structures in Wireless Power Transfer," IEEE Transactions on Magnetics, vol. 50, no. 11, pp. 1-4, nov 2014. [Online]. Available: http://ieeexplore.ieee.org/document/6971725/

[25] S. Y. R. Hui, W. Zhong, and C. K. Lee, "A Critical Review of Recent Progress in Mid-Range Wireless Power Transfer," IEEE Transactions on Power Electronics, vol. 29, no. 9, pp. 4500-4511, sep 2014. [Online]. Available: http://ieeexplore.ieee.org/document/6472081/

[26] P. J. Abatti, S. F. Pichorim, and C. M. de Miranda, "Maximum Power Transfer versus Efficiency in MidRange Wireless Power Transfer Systems," Journal of Microwaves, Optoelectronics and Electromagnetic Applications, vol. 14, no. 1, pp. 97-109, jun 2015. [Online]. Available: http://www.scielo.br/scielo.php?script=sci_arttext\&pid= S2179-10742015000100097\&lng=en\&tlng=en

[27] Y. Zhang, Z. Zhao, and T. Lu, "Quantitative Analysis of System Efficiency and Output Power of Four-Coil Resonant Wireless Power Transfer," IEEE Journal of Emerging and Selected Topics in Power Electronics, vol. 3, no. 1, pp. 184-190, mar 2015. [Online]. Available: http://ieeexplore.ieee.org/document/6803859/

[28] Zhe Liu, Han Zhao, Chunyan Shuai, and Siqi Li, "Analysis and equivalent of four-coil and two-coil systems in wireless power transfer," in 2015 IEEE PELS Workshop on Emerging Technologies: Wireless Power (2015 WoW), pp. 1-6, jun 2015. [Online]. Available: http://ieeexplore.iee.org/document/7132835/

[29] C. Xiao, K. Wei, F. Liu, and Y. Ma, "Matching capacitance and transfer efficiency of four wireless power transfer systems via magnetic coupling resonance," International Journal of Circuit Theory and Applications, vol. 45, no. 6, pp. 811-831, jun 2017. [Online]. Available: http://doi.wiley.com/10.1002/cta.2247

[30] C. M. Miranda, S. F. Pichorim, and P. J. Abatti, "On the impact of relay circuit losses in four-coil wireless power transfer systems," International Journal of Circuit Theory and Applications, vol. 47, no. 12, pp. 1922-1932, dec 2019. [Online]. Available: https://onlinelibrary.wiley.com/doi/abs/10.1002/cta.2685

[31] A. K. RamRakhyani and G. Lazzi, "Multi-coil approach to reduce electromagnetic energy absorption for wirelessly powered implants," Healthcare Technology Letters, vol. 1, no. 1, pp. 21-25, jan 2014. [Online]. Available: https://digital-library.theiet.org/content/journals/10.1049/htl.2013.0035

[32] J. Liu, X. Zhang, J. Yu, Z. Xu, and Z. Ju, "Performance Analysis for the Magnetically Coupled Resonant Wireless Energy Transmission System,” Complexity, vol. 2019, pp. 1-13, nov 2019. [Online]. Available: https://www.hindawi.com/journals/complexity/2019/6090427/ 
[33] D. M. Beams and S. G. Annam, "Validation of a reflected-impedance design method for wireless power transfer applications," in 2012 IEEE 55th International Midwest Symposium on Circuits and Systems (MWSCAS), pp. 758-761, aug 2012. [Online]. Available: http://ieeexplore.ieee.org/document/6292131/

[34] P. Silvester, Modern Electromagnetic Fields, N. Marcuvitz, Ed., Englewood Cliffs, NJ, 1968. [Online]. Available: https://archive.org/details/ModernElectromagneticFields/page/n173

[35] International Commission on Non-Ionizing Radiation Protection (ICNIRP), "Guidelines for Limiting Exposure to Electromagnetic Fields (100 kHz to $300 \mathrm{GHz}$ )," Health Physics, vol. 118, no. 5, pp. 483-524, may 2020. [Online]. Available: http://journals.lww.com/10.1097/HP.0000000000001210

[36] — " "Principles for Non-Ionizing Radiation Protection," Health Physics, vol. 118, no. 5, pp. 477-482, may 2020. [Online]. Available: http://journals.lww.com/10.1097/HP.0000000000001252 